\title{
Not So Soft Skills: \\ The Importance of Grit to College Student Success
}

Rebekah Reysen, The University of Mississippi

Matthew Reysen, The University of Mississippi

Patrick Perry, The University of Mississippi

R. Dewey Knight, The University of Mississippi

According to the American College Testing organization (2012), fewer than 35\% of students attending public institutions graduate within five years of enrolling. This figure increases to just over fifty percent for private attendees. Clearly, the idea of a "four-year degree" is more elusive for the majority of undergraduate students than it has ever been. These facts have led researchers to consider the factors that delay, or even prevent, graduation. The concept of "grit" (Duckworth, Peterson, Matthews, \& Kelly, 2007) is defined as passion and perseverance for very long-term goals and has become a popular topic in the education literature. Duckworth et al. (2007) found that grit positively associates with academic success. The purpose of the present study was to explore the relationships between grit, academic performance, and educational attainment, as measured by number of attempted credit hours at the collegiate level. We also aimed to ascertain whether academically at-risk students (those with less than a $2.0 \mathrm{GPA}$ ) had lower grit scores than their non-at-risk peers. We discuss our findings in the context of potential interventions and future directions for research in this area.

Keywords: grit, college student, academic success, retention

Institutions of higher learning from across the country continue to search for effective strategies to increase both recruitment and retention. In an era of reduced support from state legislatures, public institutions are increasingly 
dependent on tuition revenue. Administrators have sought to compensate for reduced revenue flows from state governments and avoid marked tuition increases by both recruiting more students and focusing on retention of those students.

The purpose of the present paper was to closely examine the retention aspect of this equation. There are numerous factors that have been found to contribute to student persistence, and thus, institutional retention. One factor that has recently received a lot of attention is the concept of "grit." "Grit," defined as passion and perseverance for very long-term goals, has become a popular topic in the education literature and at professional conferences. The concept of grit has been used to explain why passion and perseverance helps individuals reach their long-term goals, such as those pertaining to academic performance (Duckworth, Peterson, Matthews, \& Kelly, 2007).

More specifically, Duckworth et al. (2007) demonstrated that grade point average (GPA) was positively correlated with grit. Despite this observation, because their sample comprised students attending an Ivy League university in the northern United States, extrapolation to other types of institutions or to schools located in disparate geographic regions may be potentially problematic. Furthermore, Duckworth et al. (2007) found that students with higher levels of educational attainment scored higher on grit. At the university level, measures of educational attainment include not only GPA, but also the total number of attempted credit hours.

In an attempt to determine whether Duckworth et al.'s (2007) findings can be extended to a very different population of students, we explored the relationship between grit and academic success at the University of Mississippi, with a sample that comprised both academically at-risk (those with less than a 2.0 cumulative GPA) and non-at-risk students. We also sought to investigate whether there was a relationship between the length of time a student attended an institution and their corresponding grit score. We hoped that the results of this study would not only help higher education professionals learn more about which populations could most benefit from grit-building activities, but also how to best target specific interventions at the university-level. 


\section{Grit and Retention Literature \\ Background}

In 2014, the University of Mississippi established the Center for Student Success and First-Year Experience. The Center provides academic advising, coordinates the first-year and transfer experience courses, and supports firstyear students with programs and initiatives designed for student success. The Center also leads the University's Retention Advisory Committee, a working group of university-wide representatives charged with focusing on all of the various aspects of student retention. Institutional retention at the University of Mississippi for first-time freshmen fall to fall for the 2014 cohort was observed to be $86.5 \%$, which represented an institutional record (University of Mississippi, 2016).

Although the $86.5 \%$ retention rate is relatively high, the leadership within the Center continues to identify best practices in order to increase student success. According to the Center's report (2016), less than 10\% of the fall 2015 freshmen class who did not return for spring 2016 reported poor grades as their primary reason for discontinuance. Instead, more than $50 \%$ of departing students cited other factors (such as homesickness/distance from home, personal/family issues, social fit, and major fit) as reasons for not returning. In addition to identifying the primary reasons for departure, the Center's staff also wanted to examine the suggestion that the level of grit a student possesses influences their likelihood of academic success (Duckworth et al., 2007).

Grit (Duckworth et al., 2007) relates closely to the concept of mindset (Dweck, 2006). Dweck (2006) identified people as having either a fixed mindset or a growth mindset. A person with a fixed mindset believes that qualities such as intelligence and personality do not change. Conversely, people with a growth mindset believe that improving personal qualities occurs through effort and that failure is a temporary, natural process of learning (2006).

Duckworth et al. (2007) studied West Point military cadets to see if there was a relationship between grit and talent. Using the Grit Scale that she and her colleagues developed, Duckworth determined that talent did not correlate with the likelihood of West Point cadets completing their training, but that grit was related with retention. With talent oftentimes being touted as a key to success, 
Duckworth's findings illustrate how talent, although beneficial, is not always a significant factor in determining whether or not a person achieves their longterm goals.

In addition to goal attainment in the military, grit has also been explored in relation to marriage, the workplace, and professional competencies. For example, Duckworth, Quinn, and Seligman (2009) found that instructors who had higher levels of grit were also more effective in helping students enrolled in schools with inadequate resources better meet their academic goals. EskreisWinkler, Shulman, Beal, and Duckworth (2014) discovered that grit was a better, more significant predictor of graduating from high school, maintaining marital commitment, being a successful salesperson, and maintaining employment tenure than previously-explored variables such as physical ability, intelligence, and personality characteristics (Big Five; John \& Srivastava, 1999).

Although Duckworth and colleagues' work on grit has received a great deal of attention, some researchers have criticized the grit construct. For example, in their article entitled, "Much Ado About Grit: A Meta-Analytic Synthesis of the Grit Literature," Crede, Tynan, and Harms (2017) provide a detailed analysis of a number of articles that have been published on grit, with their investigations including 88 separate samples of more than 66,000 participants. Based on their research, these authors conclude that a relatively strong correlation between grit, retention, and participant performance is lacking. Furthermore, these authors highlight how grit has been found to be highly correlated with the personality trait conscientiousness as well as other constructs like industriousness (Jackson, Paunonen, \& Tremblay, 2000) and desire for accomplishment (McClelland, 1985), to name a few. According to these authors, this suggests that:

The conceptual similarities between these constructs and grit raises the possibility that proponents of grit may have fallen victim to what Kelley (1927) referred to as the "jangle fallacy" - the belief that two things are different simply because they have different names. (p. 12)

Furthermore, Crede et al. (2017) argue that established processes and procedures for enhancing grit are actually not as effective in helping people become successful as one would hope. 


\section{Purpose}

Students making the adjustment from high school to institutions of higher learning face numerous challenges when they work to navigate the college environment. As mentioned above, in addition to the academic skills a student possesses, their ability to overcome obstacles can also play a role in their academic success.

The present study uses the Grit Scale, developed by Duckworth et al. (2007), to assess the relationship between students' level of academic success and their grit scores. Specifically, the authors aimed to ascertain whether or not a relationship exists between grit and cumulative GPA for these participants. In addition, we were interested in whether grit scores differed between students who were academically at-risk versus their non-at-risk peers. Given that Duckworth et al. (2007) found that students who have higher levels of educational attainment are "grittier" than those with less education, we also explored whether there was a relationship between grit and the number of credit hours attempted at the collegiate level.

\section{Methods}

\section{Participants}

We received IRB approval prior to the start of the study, which was conducted during the Spring of 2015. We were interested in both academically at-risk and non-at-risk participants, so as to make a comparison between grit scores for these two distinct populations. Three hundred and four students volunteered to participate in this study.

Two questions were included to function as instructional manipulation checks. These questions involved having students choose "not like me at all for this item," for one question and choose "never" for the other question. Data from participants who did not answer these two questions correctly were excluded from subsequent analyses, as it indicated they were not following instructions. Fifty-two of the initial 304 participants answered either one or both of these "lie scale" questions incorrectly. Of these 52, 24 were non-atrisk students and 28 were at-risk students, leaving a total of 252 participants. For these remaining 252 participants, $42.5 \%$ (n=107) of the sample could be considered "at-risk" participants, while $57.5 \%(n=145)$ of participants were 
deemed "not at-risk," with 44.4\% (n=112) identified as female and 55.6\% $(\mathrm{n}=140)$ identified as male. The majority of participants identified as White (69.8\%, $n=176), 18.3 \%(n=46)$ as Black, 7.5\% $(n=19)$ as Hispanic/Latino, $.4 \%(\mathrm{n}=1)$ as Hawaiian/Pacific Islander, $1.2 \%(\mathrm{n}=3)$ as American Indian, $1.6 \%(n=4)$ as Asian, and $1.2 \%(n=3)$ as two or more races. For the most part these statistics resemble the overall undergraduate enrollment of the University of Mississippi as of the fall of 2015. Enrollment included a total of 18,084 students; $77.98 \%$ identified as White $(n=14,102), 13.27 \%$ as Black $(\mathrm{n}=2,400), 3.13 \%$ as Hispanic/Latino $(\mathrm{n}=566), .17 \%$ as Hawaiian/Pacific Islander ( $\mathrm{n}=31$ ), .36\% American Indian ( $\mathrm{n}=65)$, 3.03\% Asian ( $\mathrm{n}=548), 2.05 \%$ multiracial ( $\mathrm{n}=370)$, and .01\% unknown ( $\mathrm{n}=2)$. As for gender, however, 55.34\% of the undergraduate population identified as female $(n=10,007)$ (University of Mississippi, 2016). In the current study, the majority of the participants identified as male.

\section{Procedure}

The authors recruited academically at-risk students through the EDHE 101 Academic Skills for College course, along with the EDHE 202 Fundamentals of Active Learning class and the Contractual Readmission Program. The authors contacted these students through Blackboard, a course management system. Other students (more likely to be not-at-risk) were solicited by placing an ad on the Sona website-a research management system—for Psychology 201 Introduction to Psychology students. In exchange for their participation, both sets of participants could receive either partial course credit or extra credit.

Participants received an email which included an information document that outlined the experiment. In addition, they received a link to Qualtrics, an online data management system, which contained the informed consent document and assessments utilized in the study. When the participants initiated the survey on Qualtrics, they were asked to read the informed consent form, which stated that their data would be kept confidential, and that they had a right to terminate their role in the study at any time. The document also stated that the researchers would access their student transcripts and other demographic data using the SAP student data storage system. Once participants read the informed consent document, they were able to click on a button to give their permission to proceed with the study. Upon completion 
of the surveys, the participants read a short debriefing statement and were thanked for their participation.

After collecting the survey results, we ran a report in SAP using the students' identification numbers. In this manner, we were able to obtain students' GPAs and other demographic information. In addition, we were able to use these student identification numbers to allot course credit/extra credit. Next, we de-identified the data prior to analysis. We hoped that informing participants that their data would be de-identified before any subsequent analysis would make them more likely to be honest while completing the survey.

\section{Instrumentation}

The Grit Scale is a 12-item questionnaire that has been utilized in a variety of studies, including those pertaining to academic performance and persistence in the military (Duckworth et al., 2007). Items include those that focus on passion and goal completion, such as "I am a hard worker" and "I finish whatever I begin." One measures the level of perseverance through items such as "New ideas and projects sometimes distract me from previous ones" or "I have difficulty maintaining my focus on projects that take more than a few months to complete." Participants rank their responses from 1 (very much like me) to 5 (not like me at all). Several items require reverse-scoring. We calculated the overall grit scores by totaling scores and dividing by 12 , the number of assessment items. The highest or "grittiest" participants can receive a score of 5, while the "least gritty" participants can receive a score of "1."

In addition to the Grit Scale, we used a short form of the Marlowe-Crowne Social Desirability Scale, developed by Ballard (1992). This assessment has 11 items and measures social desirability using a 5-point Likert type scale from 1 (never) to 5 (very often). As students may want to appear or feel grittier than they actually are, we thought it was important to include a measure of social desirability to determine the extent to which this occurred.

Finally, archival data evaluated in this study included students' overall grade point average (GPA) at the university, their semester GPA, and their overall GPA including transfer work. This allowed for an overall assessment of academic performance, as students may not always be aware of exact GPA. 


\section{Results}

Of primary interest was whether or not grit would differ as a function of academic standing. We operationally defined at-risk students as those with an overall grade point average of less than 2.0. In total, 145 participants were deemed not-at-risk, whereas 107 participants were categorized as at-risk. An alpha level of .05 was adopted for all statistical analyses.

An Analysis of Variance (ANOVA) indicated that not-at-risk participants scored higher, on average, on the grit scale than their at-risk peers, $\mathrm{F}(1,250)$ $=4.60, \mathrm{MSe}=0.28, \mathrm{p}<.05, \eta \mathrm{p} 2=.02$. Thus, as hypothesized, participants who were not-at-risk were "grittier" than those students who were struggling academically.

As mentioned above, we also included a measure of social desirability. First, we conducted an ANOVA to determine whether there was a difference in social desirability between at-risk and not-at-risk students. The result of the ANOVA was not statistically significant, $\mathrm{F}(1,250)=1.06$, MSe $=0.17, \mathrm{p}>.05$, $\eta \mathrm{p} 2=.004$. Thus, the social desirability scores for both at-risk and not at-risk students appeared to be statistically equivalent.

In addition to this analysis, we also sought to determine whether any relationships existed between grit and several other measures of academic achievement. More specifically, we collected data regarding the following measures of academic achievement for each participant: resident cumulative grade point average, resident semester grade point average, resident number of credit hours attempted, and overall number of credit hours attempted the college level. This data is presented in Table 1. 
Table 1. A Comparison of Academically At-Risk (AR) Versus Non-At-Risk (NAR) College Student Groups for Demographic Variables of Resident Cumulative GPA, Resident Semester GPA, Number of Credit Hours Completed and Attempted

\section{Demographic Variable}

Resident Cumulative GPA

Mean

Standard Deviation

Resident Semester GPA

Mean

Standard Deviation

Overall GPA

Mean

1.68

Standard Deviation

Resident \# of Credit Hours Attempted

Mean

Standard Deviation
AR

NAR

0.47

0.57
4.49

0.68

4.65

55.16 40.94

42.68

With respect to effect sizes, we followed Cohen's (1992) convention ( $\mathrm{r}$ $=.1$ = small; $\mathrm{r}=.3$ = medium; $\mathrm{r}=.5=$ large $)$. Correlational analyses indicated that significant correlations occurred between grit scores and three out of the four academic measures. Grit positively correlated with resident cumulative grade point average, $\mathrm{r}(252)=.17, \mathrm{p}<.01$, resident semester grade point average, $\mathrm{r}(252)=.15, \mathrm{p}<.05$, and overall grade point average, $\mathrm{r}(252)=.21, \mathrm{p}$ $<.01$. However, we found no significant correlation between grit and resident attempted hours, $r(252)=.08, p>.05$. On the other hand, grit scores showed a negative relationship with social desirability, $\mathrm{r}(252)=-.33, \mathrm{p}<.01$. 
Demographic Variable

Grit Scores

Mean

Standard Deviation

Social Desirability

Mean

2.98

Standard Deviation
AR

NAR

3.18

0.57

0.49

\section{Discussion}

Overall, these findings replicate prior investigations into this topic by demonstrating the relationship between grit and standard measures of academic achievement. Furthermore, we also demonstrated that participants who tend to score higher in social desirability also tend to score lower on the grit scale. Finally, and perhaps most interestingly, students with higher grade point averages tend to be grittier than their academically at-risk peers.

Overall, several statistically significant results were obtained, including how grit significantly correlates with GPA, but at a relatively small effect size for this sample. Duckworth et al. (2007) also found a significant correlation between grit and academic performance, although their student population was markedly different from those who participated in the current study. Duckworth et al. (2007) polled students at an Ivy League institution, which has a very small percentage of students on academic probation. In the current study, the sample was a blend of academically at-risk and not-at-risk students. Finding this significant correlation in a variety of populations lends support for the utility of the Grit Scale; however, in our study the correlation was rather weak, suggesting that there are other extenuating factors that influence students' academic performance and persistence.

It is also interesting to note that academically at-risk students showed lower levels of grit than their non-at-risk peers. This seems intuitive, considering that academically at-risk students may have additional life 
challenges that could be interfering with their ability to pursue their academic goals. Students who previously left the institution cite specific reasons for leaving including personal/family issues, homesickness, and feeling out of place at the University (CSSFYE, 2016). Perhaps academically at-risk students are at-risk because of the nature of the problems they are experiencing. Such an assertion could be tested in future experiments. In any case, this result suggests the potential benefits of Orientation, Transition, and Retention (OTR) professionals having academically at-risk students participate in grit-building activities to enhance their passion and perseverance for completing college. As there are two key components to grit - passion and perseverance - OTR professionals can focus on helping students learn more about what they are passionate about while also teaching students how to persist in their college development. Many university career centers have access to assessments that students can take to learn more about specific career path(s) they may want to pursue. Once students have a firmer understanding as to which careers they would likely find fulfilling, students can then create schedules each semester that include courses they are passionate about, which can in turn help them maintain higher levels of motivation to do well academically. OTR professionals can also help students develop better study skills, habits, and time management techniques, which can then help them optimize their academic performance.

There were several limitations associated with this study. First, our survey results were obtained using self-reported responses. Self-report studies may not always be the most valid way of measuring a construct in a given population. Second, these results were obtained from a single public university in the Southern United States, the University of Mississippi, which may have its own idiosyncratic characteristics that differ from those of other institutions.

Third, over 50 participants were removed from the analysis due to not paying adequate attention while responding to the surveys. This may have been due to the timing in which the surveys were administered-towards the end of the semester when students were especially in need of extra credit or course credits. It is possible that we might have obtained different results had the surveys been administered closer to the beginning of the semester.

The present results do seem to have some potential implications for future research projects. First, given that a significant correlation between 
grit and social desirability was observed, we recommend that future studies utilize social desirability controls when polling participants. Without the use of such a control survey, researchers may get an inaccurate picture from the data. Additionally, we recommend pursuing additional studies that explore how students develop grit over time, as well as how grit-building activities can influence college student retention. Overall, consistent with Duckworth et al.'s (2007) results, we observed a relatively small but statistically significant correlation between grit and GPA for students polled at the University of Mississippi. This result suggests that grit is, in fact, related to academic performance. 


\section{References}

Ballard, R. (1992). Short forms of the Marlowe-Crowne Social Desirability Scale. Psychological Reports, 71, 1155-1160.

Center for Student Success and First Year Experience (2016). 2015 fall-tospring retention report. Unpublished manuscript, the University of Mississippi Retention Advisory Board.

Cohen, J. (1992). A power primer. Psychological Bulletin, 112, 155-159. doi:10.1037/0033-2909.112.1.155

Crede, M., Tynan, M. C., \& Harms, P. D. (2017). Much ado about grit: A metaanalytic synthesis of the grit literature. Journal of Personality and Social Psychology, 113(3), 492-511. doi: 10.1037/pspp0000102

Duckworth, A. L. (2016). Grit: The power of passion and perseverance. New York: Scribner.

Duckworth, A. L., Peterson, C., Matthews, M. D., \& Kelly, D. R. (2007). Grit: perseverance and passion for long-term goals. Journal of Personality and Social Psychology, 92(6), 1087-1101.

Duckworth, A. L., Quinn, P. D., \& Seligman, M. E. P. (2009). Positive predictors of teacher effectiveness. The Journal of Positive Psychology, 4(6), 540547. http://dx.doi.org/10.1080/17439760903157232

Dweck, C. (2006). Mindset: The new psychology of success. New York: Ballantine Books.

Eskreis-Winkler, Shulman, Beal, \& Duckworth (2014). The grit effect: Predicting retention in the military, the workplace, school, and marriage. Frontiers in Psychology. Retrieved from https://www. frontiersin.org/articles/10.3389/fpsyg.2014.00036/full

Jackson, D. N., Paunonen, S. V., \& Tremblay, P. F. (2000). Six personality questionnaire manual. Port Hurton, MI: Sigma Assessment Systems.

John, O. P., \& Srivastava, S. (1999). The Big-Five trait taxonomy: History, measurement, and theoretical perspectives. In L. A. Pervin \& O. P. John (Eds.), Handbook of personality: Theory and research (Vol. 2, pp. 102-138). New York: Guilford Press. 
Kelley, T. L. (1927). Interpretation of educational measurement. World Books: Yonkers-On-Hudson, NY.

McClelland, D. C. (1985). How motives, skills, and values determine what people do. American Psychologist, 40, 812-825.

University of Mississippi (2016). Mini-Fact-Book. Retrieved from http://irep. olemiss.edu/wp-content/uploads/sites/98/2016/01/Mini-Fact-Bookin-Excel_2015-2016.pdf 